\section{TÀI LIÊU THAM KHẢO}

1. Leese H.J. (1998). Human Embryo Culture: Back to Nature. J Assist Reprod Genet, 15(8), 466-468.

2. Lawitts J.A. and Biggers J.D. (1991). Optimization of mouse embryo culture media using simplex methods. J Reprod Fertil, 91(2), 543-556.

3. Dieamant F., Petersen C.G., Mauri A.L., et al. (2017). Single versus sequential culture medium: which is better at improving ongoing pregnancy rates? A systematic review and meta-analysis. JBRA Assist Reprod, 21(3), 240-246.

4. Đặng Quang Vinh, Võ Nguyên Thức, Nguyễn Ngọc Quỳnh, và cs (2017). So sánh hiệu quả tạo phôi nang giữa hai loại môi trường nuôi cấy đơn bước và môi trường nuôi cấy chuyến tiếp. Tạp chí Phụ Sản, 14(4).

5. Ahlström A., Westin C., Reismer E., et al. (2011). Trophectoderm morphology: an important parameter for predicting live birth after single blastocyst transfer. Hum Reprod, 26(12), 3289-3296.
6. Sfontouris I.A., Kolibianakis E.M., Lainas G.T., et al. (2017). Blastocyst utilization rates after continuous culture in two commercial single-step media: a prospective randomized study with sibling oocytes. J Assist Reprod Genet, 34(10), 1377-1383.

7. Cimadomo D., Scarica C., Maggiulli R., et al. (2018). Continuous embryo culture elicits higher blastulation but similar cumulative delivery rates than sequential: a large prospective study. J Assist Reprod Genet, 35(7), 1329-1338.

8. Stimpfel M., Bacer-Kermavner L., Jancar N., et al. (2020). The influence of the type of embryo culture media on the outcome of IVF/ICSI cycles. Taiwan J Obstet Gynecol, 59(6), 848-854.

9. López-Pelayo I., Gutiérrez-Romero J.M., Armada A.I.M., et al. (2018). Comparison of two commercial embryo culture media (SAGE-1 step single medium vs. G1-PLUS ${ }^{T M} / G 2-$ PLUS $^{T M}$ sequential media): Influence on in vitro fertilization outcomes and human embryo quality. JBRA Assist Reprod, 22(2), 128-133.

\title{
HIỆU QUẢ CỦA KỸ THUÂT KHÍ DUNG SÓNG CAO TẦN TRONG ĐIỀU TRI ĐỢT CẤP BÊ̂NH PHỔI TẮC NGHẼN MẠN TÍNH MỨC Độ TRUNG BÌNH
}

\section{TÓM TẮT}

Mục tiêu nghiên cứu: Đánh giá hiệu quả kỹ thuật khí dung sóng cao tần (IPV) trong điểu trị bệnh nhân đợt cấp COPD mức độ trung bình. Phướng Pháp: Nghiên cứu tiến cứu can thiệp trên 60 bệnh nhân đợt cấp COPD mức độ trung bình theo tiêu chuẩn Anthonisen 1987, vào viện tại trung tâm Cấp cứu A9 - Bệnh viện Bạch Mai từ tháng 7 năm 2020 đến tháng 7 năm 2021, các bệnh nhân tham gia nghiên cứu đước chia thành hai nhóm, 30 bênh nhân nhóm chứng và 30 bệnh nhân nhóm can thiệp IPV. Các thông số theo dõi chính như: Tuổi, giới, các chỉ số lâm sàng: mạch, nhịp thở, Sp02 tại các thời điểm nhập viện (TO), sau khí dung 60 phút (T1), 6h (T2), 12h (T3), 24h(T4), 48h(T5), 72h(T6); các chỉ số khí máu: $\mathrm{pH}, \mathrm{PaCO} 2, \mathrm{PaO}_{2}, \mathrm{HCO}^{-}$, theo dõi tại các thời điểm T0, T2, T4, T5 và T6. Bệnh nhân được đánh giá thành cống khi không phải thở máy hố trợ. Kết quả: Trong 60 bệnh nhân nghiên cứu (tuổi trung bình $69,83 \pm 9,90$ tuổi; $11,7 \%$ nữ giới) cho kết quả: Có 6 (20\%) bệnh nhân trong nhóm chứng phải chuyển thở không xầm nhập, trong khí đó ở nhóm can thiệp có 1 (3,3\%) bệnh nhân trong nhóm phải chuyển thở không xâm nhập $(p<0,05)$. Thời gian nằm viện của nhóm

${ }^{1}$ Bệnh viện Hữu nghi Việt Tiệp - Hải Phòng ²Tung tâm Cấp cứu A9-Bênh viện Bạch Mai Chịu trách nhiệm chính: Đổ Ngọc Sơn Email: sonngocdo@gmail.com Ngày nhận bài: 13.7.2021

Ngày phản biên khoa hoc: 31.8.2021

Ngày duyệt bài: 15.9.2021
Trần Văn Tân ${ }^{1}$, Đỗ Ngọc Sơn ${ }^{2}$

chứng là $8,00 \pm 2,95$ ngày, của nhóm can thiệp là $6,73 \pm 2,99$ ngày $(p=0,105)$. Có $63,3 \%$ bệnh nhân đánh giá IPV ở mức độ dế chiu (mức đô I), $26,7 \%$ bệnh nhân đáng giá ở mức độ khó chịu nhẹ (mức độ II), không có bênh nhân nào khó chiu tới mức phải dứng khí dung bằng IPV. Kết luận: IPV là một kỹ thuật an toàn và có thể ngăn chặn tình trạng xầu đi của đợt cấp trong điều trị đợt cấp bệnh phổi tắc nghẽn mạn tính mức độ trung bình, giảm tỳ lệ bệnh nhân chuyển thở máy không xâm nhập.

Tì̛ khóa: Khí dung sóng cao tần, thông khí nhân tạo không xâm nhập, bệnh phổi tắc nghẽn mạn tính.

\section{SUMMARY \\ EFFECTIVENESS OF INTRAPULMONARY PERCUSSIVE VENTILATION IN THE TREATMENT OF PATIENTS WITH MILD TO MODERATE EXACERBATION OF CHRONIC PULMONARY OBSTRUCTIVE DISEASE}

Objective: To evaluate the effectiveness of intrapulmonary percussive ventilation (IPV) in the treatment of mild to moderate exacerbations of COPD patients. Methods: Prospective interventional study on 60 patients with acute exacerbation of COPD according to Anthonisen 1987, admitted to the Center for Emergency Medicine of Bach Mai Hospital from July 2020 to July 2021, of which 30 were assigned to standard treatment, and 30 to IPV. The main variables such as age, sex, vital signs parameters: heart rate, respiratory rate, saturation of peripheral oxygen (SpO2) at the time of admission (T0), 1 hour (T1), 6 hours (T2), 12 hours hours(T3), 24 hours (T4), 48 
hours (T5), 72h hours (T6) after IPV ; arterial blood gas indices such as $\mathrm{pH}_{1} \mathrm{PaCO} 2, \mathrm{PaO}_{2}, \mathrm{HCO}^{-}$at the time of T0, T2, T4, T5, T6. The therapy was considered successful when non-invasive ventilation was avoided. Results: The study on 60 patients (mean age $69.83 \pm 9.90$ years; $11.7 \%$ women), there were $6(20 \%)$ patients in standard group who required NIV versus $1(3.3 \%)$ patient in IPV group required NIV $(p<0.05)$. The hospital stay of control group was 8.00 \pm 2.95 days, of IPV group was $6.73 \pm 2.99$ days $(p=0.105)$. There were $63.3 \%$ patients rated IPV as comfortable (Level I), $26.7 \%$ rated as mildly uncomfortable, however, there was no one withhold IPV. Conclusions: IPV is a safe technique and may prevent further deterioration in patients with acute axacerbations of COPD, reducing the need for NIV.

Keywwords: Intrapulmonary percussive ventilation (IPV), Non-invasive mechanical ventilation (NIV), Exacerbations of chronic obstructive pulmonary disease (ECOPD)

\section{I. ĐĂT VẤN ĐỀ}

Đợt cấp COPD là bệnh lý cấp cứu nội khoa hay gặp tại đơn vị cấp cứu, hồi sức tích cực, hô hấp ở mọi tuyến điều trị. Theo thống kê, trung bình mỗi năm một bệnh nhân COPD có từ 1,5 2,5 đợt cấp. Theo báo cáo tổng kết các hoạt động dự án phòng chống bệnh phổi tắc nghẽ̉n mạn tính và hen phế quản năm 2014 tỉ lệ mắc chung là 4,2\% ở người trên 40 tuổi, tỷ lệ các bệnh nhân mắc đợt cấp COPD vào điều trị tại trung tâm hô hấp bênh viên Bach Mai từ năm 1996 - 2000 là 25,1\%, đứng đầu bệnh lý về phổi ${ }^{1}$. Phản ứng viêm dường hô hấp, co thắt phế quản, tăng tiết đờm là nguyên nhân làm tăng sức cản đường thở và hình thành các bẫy khí. Thay đổi độ nhớt và độ bám dính của đờm lên bề mặt đường dẫn khí, giảm chức năng của hệ thống lông mao, dẫn đến dịch tiết đường hô hấp bị giữ lại, tạo thành các nút nhầy và không thể tống xuất ra ngoài bằng động tác ho. Đường thở vốn bị tắc nghẽn mạn tính nay bị bịt kín với các nút đờm, làm giảm khả năng thông khí, dẫn đến tỷ lệ thông khí tưới máu thấp hơn². Mặc dù đã có nhiều biện pháp điều trị tích cực nhưng tình trạng diễn biến xấu đi của đợt cấp vẫn có thể xảy ra dẫn đến tình trạng suy hô hấp cấp, cần phải thở máy hỗ trợ. Các nghiên cứu đã chỉ ra rằng chiến lược tăng thanh thải đường thở có thể là một lựa chọn hữu ích trong điều trị đợt cấp COPD ${ }^{3}$

Hệ thống khí dung sóng cao tần là sự kết hợp việc đưa thuốc giãn phế quản tới các đường thở sâu nhờ luồng khí tấc độ cao tạo ra từ một thiết bị nén khí, và việc huy động chất tiết từ đường hô hấp sâu thông qua bộ gõ trong phổi. Đây là kỹ thuật áp dụng một áp lực dương dao động (áp lực cài đặt trong khoảng $10-20 \mathrm{cmH} 20$ và tần số dao động trong khoảng $9-30 \mathrm{~Hz}$ ) thông qua một mặt lạ hoặc một ống ngậm. Dòng khí áp lực dương dao động trong cả thì thở vào và thì thở ra thông qua một dòng khí liên tục. Viêc kết hợp liệu pháp làm sạch đường thở với biện pháp khí dung thuốc giãn phế quản cho thấy lợi ích trong viêc làm giảm sức cản đường thở và tình trạng bẫy khí ở những bênh nhân có tổn thương phổi mạn tính và tăng tiết đờm như COPD. Thuốc giãn phế quản sẽ được đưa vào trong mỗi nhịp hít vào và đờm sẽ được huy động và làm sach trong mỗi thì thở $\mathrm{ra}^{4}$.

\section{II. ĐỐI TƯợNG VÀ PHƯƠNG PHÁP NGHIÊN CỨU 2.1. Đối tượng nghiên cứu.}

Tiêu chuâni lựa chon. Bênh nhân được chẩn đoán đợt cấp COPD theo tiều chuẩn Athonisen (1987): bệnh nhân đã được chẩn đoán COPD, đột nhiên xuất hiện một hoặc nhiêu các triệu chứng:

- Khó thở tăng

- Khạc đờm tăng

- Thay đổi màu sắc của đờm, đờm chuyển thành đờm mủ.

Chẩn đoán mức độ trung bình của đợt cấp COPD theo tiêu chuẩn Athonisen (1987): Bệnh nhân có 2 trong 3 triệu chứng trên.

\section{Tiêu chuân lai trừ:}

- Bênh nhân tràn khí màng phổi

- Bệnh nhân phẫu thuật vùng hàm mặt

Bệnh nhân không đồng ý tham gia nghiên cứu

\subsection{Thời gian, địa điểm nghiên cứu}

Thời gian: từ tháng 7 nằm 2020 đến tháng 7 năm 2021

Địa điểm: Trung tâm Cấp cứu A9 - Bệnh viện Bạch Mai

2.3. Thiết kế nghiên cứu: Nghiên cứu tiến cứu can thiêp.

2.4. Cỡ mẫu nghiên cứu: Tất cả các bệnh nhân vào Trung tâm cấp cứu $A 9$ - Bệnh viện Bạch Mai được chẩn đoán đợt cấp COPD mức độ trung bình. Tổng có 60 bệnh nhân.

\subsection{Qúa trình thu thập số liệu}

\subsubsection{Tiêu chuẩn đánh giá kết quả điều trị}

Thành công: Bệnh nhân không phải thở máy không xâm nhập, hay đặt ông nội khí quản thở máy

Thất bại: Bệnh nhân phải thở máy KXN hoặc đặt ống NKQ thở máy

Tiêu chuẩn thở máy không xâm nhập: Khi có ít nhất hai tiêu chuẩn sau:

- Khó thở vừa tới nặng có co kéo cơ hô hấp phu và hô hấp nghich thường.

- Toan hô hấp: 7,25 $\leq \mathrm{pH} \leq 7,35$ và/hoặc 45 $\leq \mathrm{PaCO}_{2} \leq 60 \mathrm{mmHg}$. 
- $25 \leq$ Tần số thở $\leq 35$ lần/phút.

2.5.2. Các bước tiến hành nghiên cứu

- Đối tượng nghiên cứu vào viện được hỏi tiền sử, bệnh sử, khám lâm sàng để hướng đến chẩn đoán đợt cấp COPD và các dấu hiệu suy hô hấp.

- Các thông số về cận lâm sàng: Công thức máu, CRP, sinh hóa máu cơ bản, khí máu động mạch, chụp phim phổi.

- Các thông số theo dõi chính bao gồm: Mạch, huyết áp, nhịp thở, $\mathrm{SpO}_{2}$ được thu thập tại các thời điểm: nhập viện (T0), sau khí dung 1 h (T1), 6h (T2), 12h (T3) 24h (T4), 48h (T5), 72h (T6). Các chỉ số khí máu $\left(\mathrm{pH}, \mathrm{PaO}_{2}, \mathrm{PaCO}_{2}\right.$, HCO3-) được thu thập tại các thời điểm T0, T2, T4, T5, T6.

- Bệnh nhân được chia làm hai nhóm, nhóm chứng được điêu trị theo hướng dẫn của Bộ Y tế, được khí dung bằng máy khí dung thường. Nhóm IPV bên cạnh điều trị theo hướng dẫn của Bộ Y tế, được khí dung bằng thiết bị sóng cao tần IPV.
2.6. Phân tích số liệu. Làm sạch và mã hóa dữ liệu thu thập được, nhập số liệu vào phần mềm thống kê y học để phân tích và xử lý

Kết cục chính là tình trạng bệnh nhân diễn biến nặng lên cần phải thở máy. Kết cục khác là thời gian nằm viện, sự thay đổi các chỉ số lâm sàng, khí máu. Dữ liệu được trình bày dưới dạng tần số và tỷ lệ phần trăm với biến định tính. Dạng trung bình \pm độ lệch chuẩn với các biến liên tục, hoặc trung vị với biến định lượng. So sánh sự khác biệt giữa các nhóm dùng thuật toán T-test, Chi-square, fisher-exact. Khác biệt được xem là có ý nghĩa thống kê khi giá trị kiểm định $p<0,05$.

\section{KẾT QUẢ NGHIÊN CỨU}

Có 60 bệnh nhân đủ tiêu chuẩn đưa vào

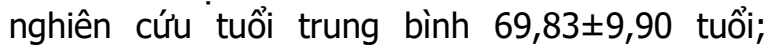
$11,7 \%$ nữ giới, và được chia thành hai nhóm. 30 bệnh nhân được khí dung bằng máy khí dung thường và 30 bệnh nhân được khí dung bằng IPV.

\section{1. Đặc điểm lâm sàng và cận lâm sàng bệnh nhân COPD khi nhập viện}

Bảng 1. Đặc điểm của bệnh nhân COPD ở hai nhóm khi nhập viện

\begin{tabular}{|c|c|c|c|}
\hline Đặc điếm & Nhóm chứng & Nhóm can thiệp & p \\
\hline Tuối & $68,2 \pm 9,89$ & $71,47 \pm 9,80$ & NS \\
\hline Thời gian bị COPD & $5,53 \pm 2,58$ & $7,76 \pm 4,85$ & NS \\
\hline CURB-65 & $0,98 \pm 0,57$ & $1,13 \pm 0,50$ & NS \\
\hline Nhịp tim & $106,52 \pm 15,68$ & $112,63 \pm 14,77$ & NS \\
\hline Tần số thơ & $24,67 \pm 3,03$ & $25,13 \pm 2,24$ & NS \\
\hline SpO2 & $90,2 \pm 3,71$ & $89,1 \pm 3,79$ & NS \\
\hline Hb & $129,66 \pm 18,82$ & $129,73 \pm 16,27$ & NS \\
\hline Bạch câu & $10,93 \pm 3,95$ & $12,03 \pm 3,95$ & NS \\
\hline CRP & $6,12 \pm 2,49$ & $6,92 \pm 3,55$ & NS \\
\hline Creatinin & $65,33 \pm 25,02$ & $64,63 \pm 17,763$ & NS \\
\hline pH & $7,38 \pm 0,58$ & $7,38 \pm 0,45$ & NS \\
\hline PaCO2 & $49,29 \pm 5,88$ & $50,7 \pm 6,4$ & NS \\
\hline PaO2 & $79,32 \pm 12,77$ & $83,12 \pm 13,21$ & NS \\
\hline
\end{tabular}

(NS: Not statistically significant)

Nhẩn xét: Đặc điểm lâm sàng, xét nghiệm huyết học, sinh hóa, và khí máu khi nhập viện giữa hai nhóm khác nhau không có ý nghĩa thống kê

3.2. Kết quả điêu trị

Bảng 2. Tỷ lệ thở máy và thời gian nằm viện của bệnh nhân COPD ở hai nhóm

\begin{tabular}{|c|c|c|c|}
\hline & Nhóm chứng & Nhóm can thiệp & p \\
\hline Thở máy KXN & $6(20 \%)$ & $1(3,3 \%)$ & $<0,05$ \\
\hline Thời gian nằm viện & $8,00 \pm 2,95$ & $6,73 \pm 2,99$ & NS \\
\hline Thở máy xâm nhậ̂p & 0 & 0 & - \\
\hline Tử vong & 0 & 0 & - \\
\hline
\end{tabular}

Nhận xét: Cả hai nhóm không có bệnh nhân phải đặt ống nội khí quản thở máy xâm nhập và không có bệnh nhân tử vong. Có 6 trong $30(20 \%)$ bệnh nhân nhóm chứng và 1 trong $30(3,3 \%)$ bệnh nhân nhóm can thiệp phải thở máy NIV, sự khác biệt giữa hai nhóm có ý nghĩa thống kê với $\mathrm{p}$ $<0,05$.

Bảng 3. Các chỉ số lâm sàng và khí máu của nhóm IPV lân khí dung lần 1

\begin{tabular}{|c|c|c|c|}
\hline & Vào viện & Sau IPV & P \\
\hline Mạch & $112,63 \pm 14,77$ & $100,23 \pm 12,36$ & $<0,05$ \\
\hline
\end{tabular}




\begin{tabular}{|c|c|c|c|}
\hline Nhịp thở & $25,13 \pm 2,24$ & $21,97 \pm 2,09$ & $<0,05$ \\
\hline Sp02 & $89,1 \pm 3,79$ & $93,9 \pm 2,04$ & $<0,05$ \\
\hline pH & $7,38 \pm 0,04$ & $7,41 \pm 0,04$ & $<0,05$ \\
\hline pCO2 & $50,7 \pm 6,4$ & $46,03 \pm 5,85$ & $<0,05$ \\
\hline
\end{tabular}

Nhân xét: Các triệu chứng lâm sàng: mạch, tần số thở, $\mathrm{Sp02}$ và các chỉ số khí máu pH, $\mathrm{PaCO} 2$ và $\mathrm{PaO} 2$ đều cải thiện sau khí dung bằng IPV 1h. Sự khác biệt của các chỉ số trên giữa trước và sau can thiệp 1h khác nhau có ý nghĩa thống kê với $p<0,05$.

Diễn biến chỉ số pH của 2 nhóm

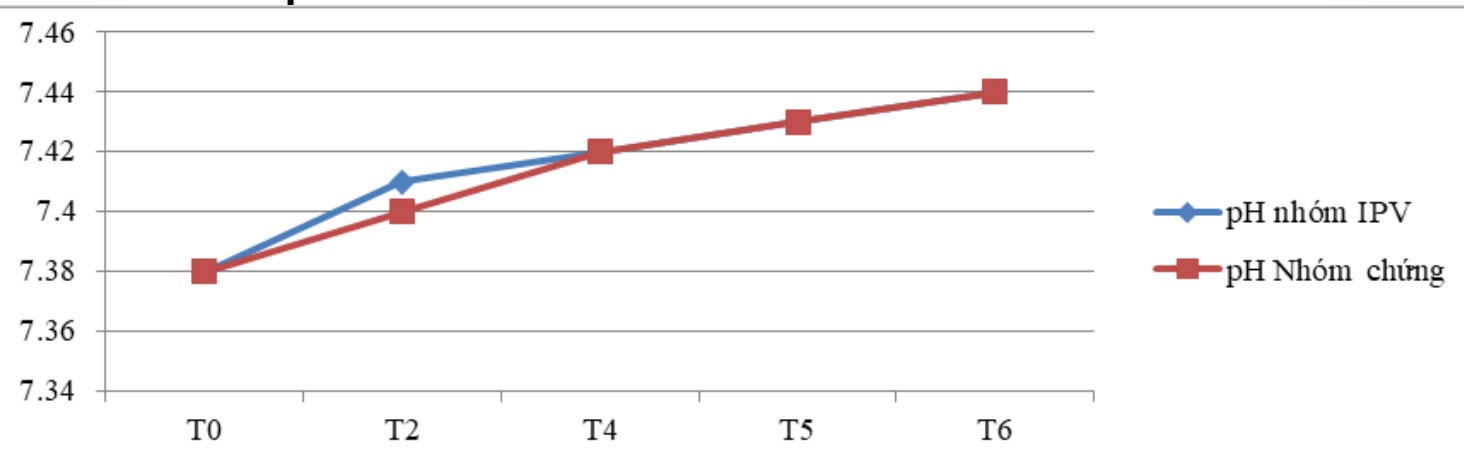

Biểu đồ 1. Diễn biến của chỉ số pH

Nhận xét: Sau khí dung lần đầu, chỉ số $\mathrm{pH}$ của nhóm sử dụng IPV cải thiện nhanh hơn so với nhóm chứng. Tuy nhiên, khi giá trị pH về giá trị bình thường thì các thời điểm theo dõi sau, không có sự khác nhau giữa hai nhóm

Diễn biến chỉ số $\mathrm{PaCO} 2$ và $\mathrm{PaO2}$ của hai nhóm

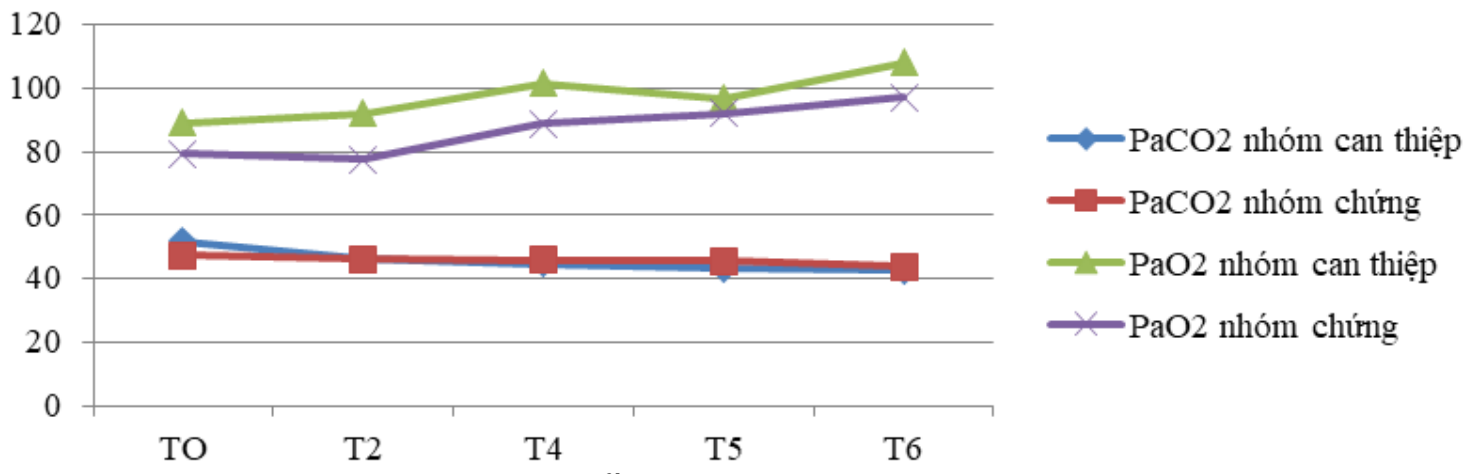

Biểu đồ 2. Diễn biến chi số PaCO2 và PaO2

Nhân xét: Các chỉ số khí máu $\mathrm{PaCO} 2$ và $\mathrm{PaO} 2$ đều cải thiện và ổn định qua các thời điểm. Đặc biệt PaCO2 trong nhóm can thiệp giảm mạnh sau lần khí dung đầu tiên.

\subsection{Tác dụng không mong muốn khi tiến hành IPV}

Tác dụng không mong muốn khi tiến hành IPV

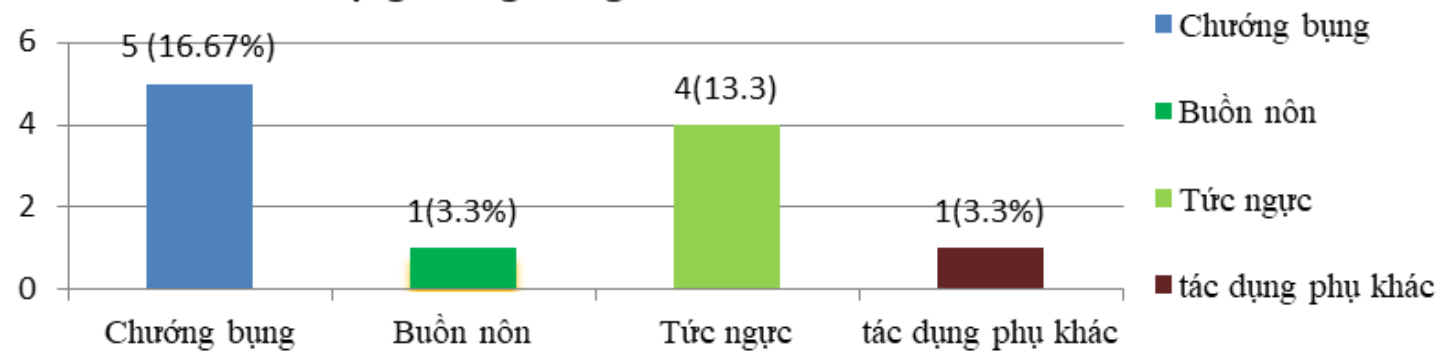

Biểu đồ 3. Tác dụng không mong muốn khi tiên hành IPV 
Mức độ dung nạp của bệnh nhân

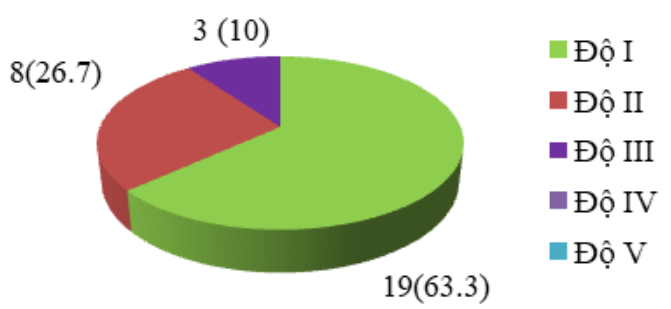

Biểu đồ 4. Mức độ dung nạp của bệnh nhân.

Nhận xét: Khi tiến hành IPV,dòng cao nhất cài đặt cho bệnh nhân là 38 lít/phút, dòng thấp nhất là 28 lít/phút, và dòng trung bình là $33,44 \pm 2,48$. Có 5 bệnh nhân $(16,67 \%)$ có cảm giác chướng bụng, 4 bệnh nhân $(13,33 \%)$ có cảm giác tức ngực, có 1 bệnh nhân $(3,3 \%)$ có cảm giác buồn nổn và 1 bệnh nhân có cảm giác mỏi miệng. Có 19 bệnh nhân (63,3\%) bệnh nhân đánh giá IPV ở mức độ dễ chịu, không có bất tiện nào. Có 8 bệnh nhân $(26,7 \%)$ bệnh nhân đánh giá mức độ khó chịu nhẹ, không có bệnh nhân nào cảm thấy khó chịu phải yêu cầu dừng khí dung bằng IPV.

\section{BÀN LUÂN}

Tuổi trung bình trong nghiên cứu của chúng tôi là $69,83 \pm 9,90$, trong đó nhóm chứng là $68,2 \pm 9.89$ và nhóm can thiệp là $71,47 \pm 9,80$. Theo nghiên cứu của Nguyễn Quang Đợi, Chu Thị Hanh và cộng sự tại Trung tâm hô hấp bệnh viện Bạch Mai từ tháng 5 năm 2015 đến tháng 9 năm 2018, tuổi trung bình của bệnh nhân COPD là $70,2 \pm 9,3$. Số năm trung bình bị COPD trong nghiên cứu của chúng tôi là $6,65 \pm 4,0$ năm, trong nghiên cứu của Nguyễn Quang Đợi, Chu Thị

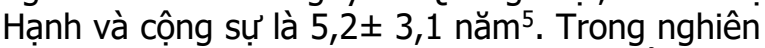
cứu của Frédéric Vargas và cộng sự, tuổi trung bình của nhóm can thiệp $70,2 \pm 5,0$ và của nhóm chứng là $69,2 \pm 6,0^{6}$

Đặc điểm khí máu của bệnh nhân đợt cấp COPD mức độ trung bình trong nghiên cứu của chúng tôi là pH: 7,38 $\pm 0,05$, PaCO2: 49,5 $\pm 6,02$, PaO2: $84,2 \pm 12,81$. Như vậy, có thể nhận thấy, hầu hết các bệnh nhân đợt cấp COPD mức đố trung bình đều có tình trạng toan hô hấp. Kết quả của chúng tôi cũng tương tự như nghiên cứu của Nguyễn Thanh Hồi, Phan Thị Hạnh tại trung tâm Hô hấp bệnh viện Bạch Mai, nghiên cứu trên 57 bệnh nhân đợt cấp COPD nhận thấy $\mathrm{pH}: 7,35$ $\pm 0,95$, PaCO2: 58 $\pm 7,3$ và $\mathrm{PaO} 2: 69,28 \pm 12,8^{7}$

Sự thay đổi các chỉ số khí máu của chúng tôi sau khi khí dung IPV một giờ cũng có sự khác biệt có ý nghĩa với $p<0,05$. Trong nghiền cứu của Frédéric Vargas và cộng sự, sau khi IPV khí máu của bệnh nhân cũng thay đổi có ý nghĩa về chỉ số pCO2 và $\mathrm{pO2}$, nhưng sự thay đổi về chỉ số pH không có ý nghĩa thống kế. Thay đổi khí máu là một mắt xích quan trọng trong sinh lý bệnh COPD. Sự tổn thương đường thở và phá hủy các phế nang, hình thành các bẫy khí là cơ chế chính gây ứ đọng khí $\mathrm{CO} 2$ và giảm khí $\mathrm{O} 2$

Trong nghiên cứu này, việc sử dụng IPV đã giúp cải thiện tình trạng lâm sàng, giảm công hô hấp và cải thiện khí máu cho bệnh nhân đợt cấp COPD mức độ trung bình. Khi so sánh với bệnh nhân sử dụng máy khí dung thường, những bệnh nhân được sử dung máy khí dung IPV có tỷ lê phải chuyển thở NIV thấp hơn, $3.3 \%$ so với $20 \%$. Điều này cũng tương tự trong nghiên cứu của Frédéric Vargas và cộng sự, tiến hành trên 33 bênh nhân được chia làm hai nhóm. Có 6/17 bệnh nhân nhóm chứng phải chuyển thở NIV và không có bệnh nhân nào trong 16 bệnh nhân nhóm can thiệp bằng khí dung IPV phải chuyển thở NIV 6

Thời gian nằm viện trung bình trong nghiên cứu của chúng tôi có sự khác nhau giữa nhóm chứng và nhóm IPV là $8,00 \pm 2,95$ ngày so với

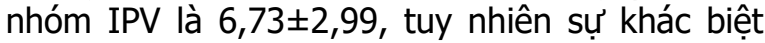
này không có ý nghĩa thống kê. Số ngày nằm viện trung bình trong nghiên cứu của chúng tôi cũng tương tự trong nghiên cứu của Frédéric Vargas và công sự. Tuy nhiên, sự khác nhau thời gian nằm viện trong nghiên cứu của Frédéric Vargas của nhóm chứng $7,9 \pm 1,3$ ngày và nhóm can thiệp là $6,8 \pm 1,0$ ngày, và sự khác bệt này có ý nghĩa thống kế

Mức độ dung nạp của bệnh nhân khi tiến hành IPV. Trong nghiên cứu của chúng tôi, có 19 bênh nhân $(63,3 \%)$ bênh nhân đánh giá IPV ở mức đô dễ chiu (Mức đô I), không có bất tiên nào. Có 8 bệnh nhân $(26,7 \%)$ bệnh nhân đánh giá mức độ kho chịu nhe (mức độ II), không có bênh nhân nào cảm thấy khó chịu phải yêu cầu dừng khí dung bằng IPV. Trong nghiên cứu của Nicolini, Russo và cộng sự $100 \%$ bệnh nhân cảm thấy thoải mái (mức độ I và II) khi tiến hành IPV, không có bệnh nhẩn nào khó chịu phải yêu câu dừng IPV ${ }^{8}$

\section{KẾT LUẬN}

Sử dụng thiết bị khí dung sóng cao tần IPV có thể ngăn chặn tình trạng xấu đi của đợt cấp trong điều trị đợt cấp COPD mức độ trung bình, cả về triệu chứng lâm sàng, khí máu và tỷ lệ 
chuyển thở máy NIV. Kỹ thuật IPV được bệnh nhân dung nạp tốt. Tuy nhiên, cần phải có nghiên cứu can thiệp ngẫu nhiên ở quy mô lớn hơn để làm rõ vai trò của IPV trong điều trị đợt cấp COPD.

\section{TÀI LIỆ THAM KHẢO}

1. Nguyễn Viết Tiến, Ngô Qúy Châu, Lương Ngoc Khuê (2018) Hướng dẫn chẩn đoán và điêu tri bềnh phổi tắc nghẽn man this. Nhà xuất bản Y hoc.

2. Hogg JC, McDonough JE, Suzuki M (2013). Small Airway Obstruction in COPD. N. Engl. J. Med. $365,1567-1575$

3. Fernandez-Restrepo $L$, Shaffer $L$, Amalakuhan B, Restrepo MI, Peters J, Restrepo R (2017). Effects of intrapulmonary percussive ventilation on airway mucus clearance: A bench model. World J Crit Care Med. 6, 164-171.

4. Osadnik CR, McDonald CF, Holland AE (2013). Advances in airway clearance technologies for chronic obstructive pulmonary disease. Expert Rev Respir Med. 2013;7, 673-685

5. Nguyễn Quang Đợi, Chu Thi Hanh và công sứ (2019) Nghiên cứu đặc điểm lâm sàng, cận lâm sàng và một số yếu tố nguy cơ tắc động mạch phỏi cấp ở bệnh nhân đợt cấp bệnh phổi tắc nghẽn mạn tính. Tạp chí Y học Việt Nam

6. Frédéric Vargas, Hoang Nam Bui, et al (2015). Intrapulmonary percussive ventilation in acute axacerbations of COPD patients with mild respiratory acidosis. A raldomized controlled trial. Critical Care. 382 - 389 - 2005.

7. Nguyễn Thanh Hồi và công sự (2013) Nghiên cứu đắc điểm lâm sàng, x-quang phổi, và kết quả khí máu ở bênh nhân đợt câp bệnh phổi tắc nghẽn man tính tại trung tâm hô hấp - bênh viện Bạch Mai. Tap chí Lao và bệnh phổi (15) 44-49.

8. Nicolini A, Russo D, Grecchi B. (2018) Comparison of Intrapulmonary Percussive Ventilation and High Frequency Chest Wall Oscillation in Patients With Severe Chronic Obstructive Pulmonary Disease. Internationa Journal of COPD, 617-625.

\title{
HIẾU QUẢ THỤ TINH TRONG ỐNG NGHIỆM BẰNG TINH TRÙnG TRÍCH XUẤT TẠI BỆNH VIỆN ĐẠI HỌC Y HÀ NộI
}

\author{
Nguyễn Khang Sơn ${ }^{1}$, Dương Tiến Tùng ${ }^{1}$
}

\section{TÓM TẮT}

Muc tiêu: Đánh giá hiệu quả và tìm hiểu một số yếu tố ảnh hưởng của phương pháp thụ tinh ống nghiêm (IVF/ICSI) sử dụng tinh trùng trích xuất. Phương pháp: Mô tả hồi cứu trên 77 chu kỳ thụ tinh ống nghiệm sử dụng tinh trùng trích xuất (64 trường hợp từ mào tinh và 13 trường hợp từ tinh hoàn), tại Trung tâm Hố trớ sinh sản và Cồng nghể Mô ghép Bệnh viện Đại học Y Hà Nội, giai đoạn 2018-2020. Kết quả: Tỷ lê thu tinh là $77,1 \%$ (trên số noãn ICSI), tỷ lệ có thai là $67,5 \%$ và tỷ lệ trẻ sinh sống là $57,1 \%$ (trên số chu kỳ IVF). Không có sự khác biệt về kết quả khi sử dụng tinh trùng trích xuất từ mào tinh hoặc từ tinh hoàn. Tuổi người chồng và thời gian vô sinh không ảnh hưởng tới tỷ lệ có thai. Kết luận: Thụ tinh ống nghiệm bằng tinh trùng trích xuất là phương pháp điêu trị có hiệu quả cho bệnh nhân vô tinh.

Từ khóa: vô tinh, tinh trùng trích xuất, ICSI, PESA, MESA, TEFNA, TESE.

\section{SUMMARY}

THE OUTCOME OF IN VITRO FERTILIZATION

USING RETRIEVED SPERMS IN HANOI

MEDICAL UNIVERSITY HOSPITAL

Objectives: The aim of this study was to

${ }^{1}$ Trường Đại hoc Y Hà Nội

Chịu trách nhiệm chính: Dương Tiến Tùng

Email: Duongtunghmu@gmail.com

Ngày nhận bài: 19.7.2021

Ngày phản biên khoa hoc: 6.9.2021

Ngày duyệt bài: 20.9.2021 evaluated IVF/ICSI outcome by using retrieved sperms and some influencing factors. Methods: Retrospective descriptive study in 77 IVF cycles used retrieved sperms in Hanoi Medical University Hospital in the period 2018 - 2020. Results: In 77 cases, 64 cases used epididymal sperm and testicular sperm was used in the remaining 13 cases. Fertilization rate, pregnancy rate and live birth rate were $77,1 \%, 67,5 \%$, and $57,1 \%$, respectively. No significant differences were found between the outcomes of patients who used epididymal as well as testicular sperm. Paternal age and duration of infertility have no effect on the pregnancy rate. Conclusion: IVF using retrieved sperms is an efficient method in cases of azoospermia.

Keywords: Azoospermia, retrieved sperm, PESA, MESA, TEFNA, TESE.

\section{I. ĐĂT VẤN ĐỀ}

Vô sinh hiên nay đã trở thành vấn đề thời sự của tất cả các quốc gia trên thế giới. Khoảng $50 \%$ các trường hợp vô sinh có nguyên nhân liên quan đến nam giới, trong đó các trường hợp vô tinh (azoospermia) - không có tinh trùng trong tinh dịch chiếm từ $10-20 \%$ [1].

Tiểm tinh trùng vào bào tương của noãn ICSI (Intracytoplasmic sperm injection) là phương pháp điều trị phố biến cho nam giới vô tinh. Tinh trùng trích xuất từ mào tinh hoặc tinh hoàn bằng nhiêu phương pháp khác nhau như PESA (choc hút mào tinh qua da), TEFNA (choc hút tinh hoàn bằng kim nhỏ), TESE (phẫu thuật 